\title{
PROPOSTA DE CLASSIFICAÇÃO E GÊNESE DAS LAGOAS DA BAIXA NHECOLÂNDIA-MS COM BASE EM SENSORIAMENTO REMOTO E DADOS DE CAMPO
}

\section{TEODORO ISNARD RIBEIRO DE ALMEIDA, ${ }^{1}$ JOEL BARBUJIANI SÍGOLO ${ }^{1}$, ERMÍNIO FERNANDES ${ }^{2}$, JOSÉ PEREIRA DE QUEIROZ NETO², LAURENT BARBIERO ${ }^{3} \&$ ARNALDO YOSO SAKAMOTO ${ }^{4}$}

\begin{abstract}
APPLIED REMOTE SENSING IN THE LAKES OF LOW NHECOLANDIA WETLANDS: CLASSIFICATION AND GENESIS DISCUSSION The Low Nhecolândia wetland lakes constitute a constant scientific challenge. The main morphological units of this area are the cordilheiras, small elevations covered by arboreal vegetation, vazantes, a drainage feature distributed over main part of the area with subtly defined channels and corixos, perennial watercourses other than the vazantes. Landsat 5 TM images supply a synoptic vision of the main elements in this environment as well as changes in biological activity and physical-chemical lake characteristics. Field data on $\mathrm{pH}$ and electric conductivity of the water table was obtained after manual drilling in seventy-seven lakes. The Landsat images allowed correlation on a broad scale of lake alkalinity/salinity with respect to cordilheiras, which provide important information on the classification and evolution of the lakes. The results suggest classification of the investigated lakes in two great groups: alkaline and non-alkaline lakes. In the former, field data revealed at least two groups of lakes, i.e., hyper-alkaline and alkaline. Each has physical-chemical peculiarities evident in the data on the phreatic aquifer. From a geochemical point of view, spatial relationship of the cordilheiras and lakes is suggestive of acidification and filling of the alkaline lakes, simultaneous with the erosion of the cordilheiras.
\end{abstract}

Keywords: Remote sensing, alkaline lackes, Pantanal da Baixa Nhecolândia, classification, genesis

Resumo As lagoas do Pantanal da Baixa Nhecolândia, constituem desafio científico constante. As denominações locais dos principais elementos morfológicos deste ambiente são as cordilheiras, pequenas elevações com vegetação arbórea, as vazantes, as drenagens parcamente definidas que ocupam grande parte da área no período das cheias, e os corixos, cursos d'água definidos e mais perenes que as vazantes. As imagens TM do satélite Landsat 5, fornecem visão sinóptica dos principais elementos do meio e, indiretamente, as características físico-químicas dos corpos d'água, ao menos em parte por condicionarem a atividade biológica. Dados de campo consistiram da amostragem de água em furos de trado em setenta e seis lagoas, com medidas de $\mathrm{pH}$ e condutividade elétrica da água do freático e de algumas águas de superfície, quando presentes, pois a coleta realizou-se no período de estiagem, com muitas lagoas secas. As imagens permitiram correlacionar, em larga escala, a alcalinidade/salinidade dos corpos d'água com a disposição das cordilheiras e vazantes, fornecendo subsídios ao estudo da gênese deste ambiente e evidenciando a possibilidade de classificar o universo investigado de lagoas em dois grandes grupos: alcalinas e não alcalinas. Nas primeiras, os dados de campo permitem distinguir pelo menos dois grupos, a saber: lagoas hiperalcalinas e lagoas alcalinas. Cada grupo exibe peculiaridades quanto a seus parâmetros físico-químicos de suas águas. A relação espacial das cordilheiras e lagoas, considerando-se seus aspectos geoquímicos, sugere acidificação e assoreamento das lagoas alcalinas, em paralelo à erosão das cordilheiras.

Palavras-chaves: Sensoriamento remoto, lagos alcalinos, Pantanal da Baixa Nhecolândia, classificação, gênese

INTRODUÇÃO OPantanal, localizado na Bacia do Alto Paraguai, embora sujeito a ampla divulgação na mídia nacional e internacional, é ainda deficientemente conhecido, em decorrência de sua complexidade e diversidade. Esta ampla região (Fig. 1) pode ser subdividida em diversos compartimentos (Brasil 1982), dos quais o Pantanal do Taquari, leque aluvial do mesmo rio, e cuja aba sul foi denominada, por vários autores, de Pantanal da Nhecolândia. O curioso nome deve-se ao apelido do filho do Barão de Vila Maria, que recuperou e povoou a região após a Guerra do Paraguai, na segunda metade do século XIX (Valverde 1972).
Descrições das características geomorfológicas são encontradas em Ab'Saber (1988) e descrições morfológicas detalhadas em Almeida \& Lima (1959). A descrição das lagoas formadas durante as enchentes levou à identificação de certa alcalinidade e salinidade das suas águas. Nesta linha, destaca-se o trabalho pioneiro de Cunha (1943), que produziu os primeiros resultados sobre os graus de salinidade e composição química das águas de algumas lagoas. Naquela época, o autor destacava o caráter salobro de algumas águas, principalmente subterrâneas, e apontava a existência de sais de magnésio, cálcio e sódio, com indicações secundárias de

\footnotetext{
1 - Departamento de Geologia Sedimentar e Ambiental, Instituto de Geociências, Universidade de São Paulo. Rua do Lago, 562, Cidade Universitária, CEP 05508-080, São Paulo (SP), Brasil. E-mail: talmeida@usp.br, jbsigolo@usp.br

2 - Departamento de Geografia, Universidade de São Paulo C.P. 8105, CEP 05508-900, São Paulo (SP), Brasil. E-mail: laboped@usp.br,

3 - IRD-CEFIRSE, Indian Institute of Science, Department of Metallurgy, 560 012, Bangalore, Índia, E-mail: barbiero@metalrg.iisc.ernet.in

4 - Departamento de Geografia, Campus de Três Lagoas, UFMS.
} 


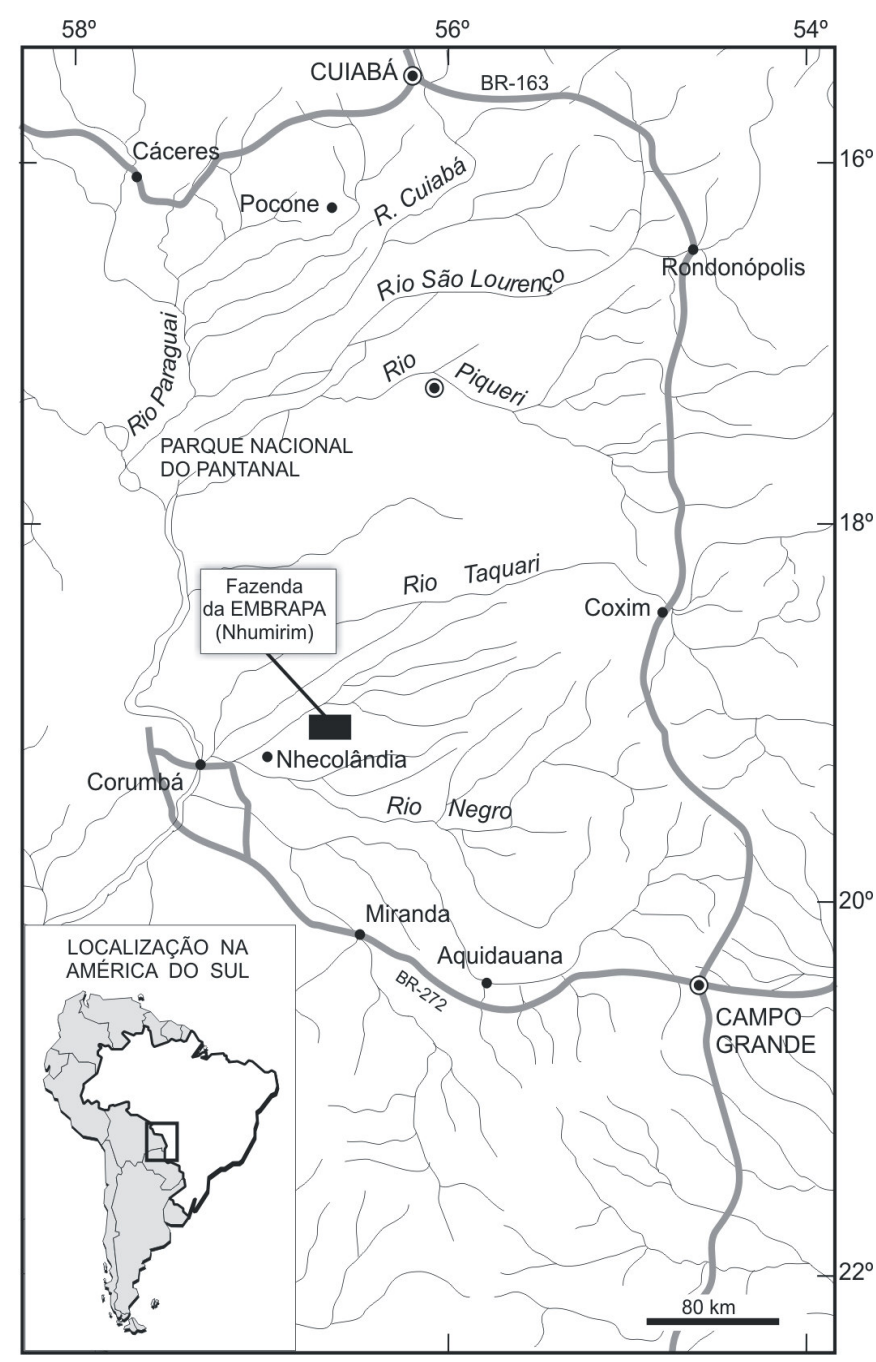

Figura 1 - Mapa de localização da área de estudo. Modificado de Antas \& Nascimento (1996).

potássio, associados a carbonatados e sulfatados. Diferentes trabalhos nesta linha foram produzidos posteriormente. A partir de 1986, firmou-se no cenário nacional o Simpósio sobre Recursos Naturais e Sócio-econômicos do Pantanal, já em terceira edição (2000), e que agrupa diferentes trabalhos sobre as lagoas da região. Hamilton et al.(1995) delimitam a produção de $\mathrm{CO}_{2}$ como vetor principal da existência de metano nestas lagoas. Posteriormente, Hamilton et al. 1996 mostram dados sobre os efeitos da variabili-dade atmosférica e das chuvas na organização e desenvolvimento das diferentes feições aquosas do pantanal (corixos, vazantes, lagoas).

As aplicações anteriores de sensoriamento remoto na análise do sistema da Nhecolândia são pouco numerosas e abordam principalmente o aspecto espacial dos padrões de inundação e da densidade de distribuição de corpos d'água. Braun (1977), Brasil (1982) e Hamilton et al. (1996) trabalharam com imagens da faixa das microondas, o que limita o estudo do comportamento espectral das águas livres, com resposta apenas no domínio óptico. Fernandes et al. (1999) e Fernandes (2000), mediante imagens TM do satélite Landsat 5, embora não tenham discutido sistematicamente a questão, verificaram que as salinas são quase sempre envolvidas por cordilheiras, em geral perenes e apresentam baixa reflectância na banda TM5 (1650nm) quando com água livre, enquanto a resposta nas demais lagoas é nula. Capellari (2001) aborda as respostas espectrais das áreas não inundadas e das de água livre. Nas áreas não inundadas, correlaciona a densidade de cobertura vegetal intensa com áreas elevadas em relação às vizinhas, corroborando com trabalhos anteriores (Fernandes et al. 1999, Fernandes 2000). Com respeito aos corpos d'água, Capellari (2001) distingue, em imagens do período de seca, lagoas (água doce e ácida) de salinas (água salgada e alcalina), utilizando métodos de classificação supervisionada pela máxima verossimilhança.

A literatura de sensoriamento remoto de lagos exibe, além da detecção da turbidez, respostas espectrais de pigmentos fotossintetizantes, matéria orgânica dissolvida e húmus aquático (Brivio et al. 2001).

Apesar dessa produção científica, ainda persiste pequeno conhecimento sobre a disposição geográfica de lagoas alcalinas/ salinas e sobre os parâmetros físico-químicos que regem sua existência. Apesar dos trabalhos recentemente publicados sobre aspectos da salinidade destas lagoas (Barbiero et al. 2000, 2002), ressente-se ainda de quadro classificatório e de identificação das diferentes variedades de lagoas, com o estabelecimento dos processos que induzem a alcalinidade/salinidade. Parte desta investigação vem sendo desenvolvida na Universidade de Paris 7 por Denis Diderot, em convênio CAPES-COFECUB(FFLCH-USP-Paris 7). Fundamentando-se nestas considerações, e apoiado pela pesquisa mencionada, é que se apresenta este trabalho, realizado na baixa Nhecolândia, porção SSW do Leque do rio Taquari, onde ocorrem milhares de lagos com salinidade e alcalinidade variáveis, em uma topografia quase plana (Fernandes 2000).

Neste trabalho propõe-se a classificação e gênese das lagoas da Baixa Nhecolândia, baseando-se em sensoriamento remoto, dados físico-químicos das águas subterrâneas sob as lagoas e a fisiografia local (condições climáticas, geomorfológicas e de coberturas vegetais). Estes lagos alcalinos resultam da conjugação de fatores morfológicos, hidrogeológicos, cobertura vegetal e mudanças climáticas. Já os lagos não alcalinos resultam da ação das águas das vazantes. Esta proposta genética é, entretanto, complexa e exige investigações mais detalhadas.

CONTEXTOGEOLÓGICO Klammer(1982) enfatizoua origem dos diferentes sedimentos do Pantanal do Mato Grosso, como provenientes da erosão de rochas Paleozóicas da Bacia do Paraná, principalmente das fácies eólico-nerítico-arenoso. Advogou claramente que estas rochas foram trabalhadas por ação eólica em condições de clima desértico e formação de dunas, as quais foram modificadas e retomadas por mudança climática para ambiente úmido. Tricart (1984) descreve o substrato das lagoas e das chamadas "cordilheiras" proveniente de processos fluviais e eólicos, desenvolvidos sob distintos ciclos climáticos que favoreciam um ou outro ambiente, construindo assim a planura pantaneira atual com sua peculiaridade geomorfológica. Clapperton (1993) demonstra ser difícil propor uma origem eólica/fluvial como advogam Klammer (1982) e Tricart (1984), em face da ausência de dados estratigráficos que permitam a construção cronológica e evolutiva do Pantanal sob modelo de bacia de deflação associada à formação de dunas em ciclos alternados. Desta forma, permanece a controvérsia sobre a origem do substrato do Cone de Dejeção do Rio Taquari. Brasil (1982) propos o termo Formação Pantanal para designar os sedimentos da depressão do Rio Paraguai e das planícies do pantanal mato-grossense descritos por Oliveira \& 
Leonardos (1943). Esta, segundo aqueles autores, compreende sedimentos aluviais arenosos, síltico-argilosos e argilosos, inconsolidados ou semiconsolidados, com freqüência areias quartzosas provenientes das rochas da Bacia do Paraná. A espessura da Formação Pantanal varia de $40 \mathrm{~m}$ a $300 \mathrm{~m}$ em sondagens executadas pela Petrobrás (Weyler 1962).

Ussami et al. (1999) delimitaram mais precisamente este espessamento, introduzindo novos conceitos quanto à estrutura flexural que originou o Pantanal. Os autores demonstram que a sedimentação na área é controlada e formada por soerguimento e extensão flexural da porção superior da crosta mecanicamente reativada no Neoproterozóico, gerando assim a depressão com mais de $200 \mathrm{Km}$ de extensão, conhecida hoje como Pantanal da Nhecolândia. Os autores empregam dados gravimétricos, reflexão sísmica, de sondagens realizadas pela Petrobrás e topografia digital. A principal fase de subsidência desta área se relaciona à reativação de falhas normais, evidentes na borda oeste da área, gerando fluxo compressional e soerguimento dos Andes centrais, no decorrer do Plioceno Superior ao Pleistoceno Inferior (2,5 Ma).

CARACTERIZAÇÃOdAÁREA Contexto Morfológico,climático e hídrico Os principais elementos da paisagem do Pantanal são baías, salinas, cordilheiras, vazantes e corixos (Almeida \& Lima 1959). As "baías" são corpos d'água em geral sazonais de baixa salinidade, abastecidos nos períodos de cheia pela água de chuva e pelo lençol freático e mantém, mesmo nas cheias, presença de vegetação. As "salinas" são lagoas de salinidade alta e que permanecem cheias por mais tempo que os demais corpos d'água. Estas são, em geral, preservadas nas cheias, tanto por possuírem depósitos salinos impermeáveis ao nível freático, como seu isolamento entre "cordilheiras" representadas por pequenas elevações de até $4 \mathrm{~m}$ de altura e cobertas por florestas ou arbustos. As "vazantes" são drenagens amplas, pouco definidas com até poucos quilômetros de largura. São limitadas por "cordilheiras", com as quais podem interagir de forma complexa, formando séries de lagoas coalescentes no ápice das cheias. As "vazantes", quando desenvolvem seções transversais bem definidas, passam a ser chamadas de "corixos" ou "corixões" (Carvalho 1986), porém também caracterizados pela maior perenidade das águas.

Os trabalhos de campo realizados mostraram que a dinâmica de inundações sazonais é controlada cronologicamente pela secagem das lagoas e implica, necessariamente, na coexistência de estágios diferentes na evolução sazonal dos corpos d'água. Após as cheias, as lagoas mais rasas secam, enquanto as mais profundas, em geral alcalinas e salinas se mantém, com praias de areia alva. Com a continuidade da estiagem, as lagoas alcalinas evaporam, aumentando a salinidade e criando ambiente propício para infestação de algas diversas. Persistindo a estiagem, o nível das águas diminui e expõe o fundo coberto por matéria orgânica, eventualmente coberta por fina camada de sais.

Implicações do ambiente na análise por sensoriamento remoto As situações mencionadas persistem, implicando em respostas espectrais diferentes dos corpos d'água similares em diferentes momentos da sua evaporação. As implicações disto para o sensoriamento remoto são desfavoráveis para uma leitura mais correta, uma vez que, no momento da obtenção da imagem, corpos d'água distintos exibirão comportamentos similares e vice-versa. Mas a região é ampla e de acesso nem sempre fácil e o sensoriamento remoto permite uma visão sinóptica que, considerada e compreendida a coexistência de diferentes momentos da evolução anual, auxilia a compreensão da origem e evolução deste particular conjunto de corpos d'água. O sensoriamento remoto fornece dois grupos de informação independentes: respostas espectrais das lagoas, indiretamente associadas à alcalinidade/salinidade e as relações diretas, espaciais, das cordilheiras com as lagoas e vazantes ou corixos. A visão sinóptica assim fornecida auxilia a aprimorar a classificação dos corpos d'água do Pantanal da Nhecolândia bem como a compreensão do funcionamento do meio.

Em princípio, os corpos d'água da Nhecolândia são suficientemente diferentes para classificá-los por sensoriamento remoto multiespectral, devido às variações de $\mathrm{pH}$, condutividade elétrica relacionada à salinidade e seus reflexos sobre a atividade biológica nas águas.

Julgou-se prioritário buscar um método para identificar as lagoas alcalinas por sensoriamento remoto com controle de campo e identificação dos parâmetros físico-químicos das águas subterrâneas ( $\mathrm{pH}$, Temperatura $\mathrm{em}^{\circ} \mathrm{C}$ e condutividade elétrica - $\mathrm{CE}$, em mS/ $\mathrm{cm}$ ), já que a alcalinidade parece desempenhar papel fundamental na gênese dos milhares corpos d'água da região. Considerou-se a água subterrânea como parâmetro de caracterização das águas, uma vez que a maioria das lagoas estavam secas durante os trabalhos de campo, evido à acentuada estiagem de outubro de 2002.

\section{MATERIAIS E MÉTODOS EMPREGADOS Sensoriamento}

Remoto Para o processamento digital utilizou-se uma imagem TM, do satélite Landsat 5, de 21.10.1990. Apesar de disponível uma imagem quase simultânea aos trabalhos de campo (ETM+ Landsat 7, de 28/09.2002), a de 1990 foi escolhida por representar um momento de fim do período de seca, mas com expressiva superfície de água livre na maior parte das salinas e baías. Na imagem de setembro de 2002, momento de seca anômala e não representativa do ciclo anual, a quase totalidade das lagoas estava seca, incluindo as salinas. Assim, a condição da imagem de 1990 foi considerada ideal, por representar melhor o ciclo anual de cheias e secas nesta área. Esta imagem permitiu analisar e detectar diferentes classes de lagoas pela resposta espectral da superfície do corpo d'água, profundamente modificada pela atividade biológi$\mathrm{ca}$, principalmente nas de maior $\mathrm{pH}$ e salinidade (diretamente relacionada à $\mathrm{CE}$ medida). Observe-se que a dinâmica do ambiente implica em mudanças sensíveis em uma década. Assim, a fisiografia local apresentou mudanças entre 1990 e 2002, mas o quadro geral se manteve e permitiu relacionar dados de 1990 e 2002.

Partindo do conhecimento prévio das características de três salinas da fazenda Nhumirim, da Embrapa, foram tomadas amostras para leitura da radiância média de 9 pixels de água, após a correção atmosférica pelo algoritmo do ER-Mapper 6.1, baseado no método da subtração do pixel escuro (Chavez (1975). Estes três corpos d'água, embora com características gerais de salinas, no conceito tradicional da região, são profundamente diferentes entre si, como confirmado em campo.

Embora o ideal em uma pesquisa que envolva sensoriamento remoto seja coletar água de superfície, dada a inexistência de água livre na maior parte dos corpos d'água, optou-se coletar em furos de trado rasos, a maioria com cerca de $1 \mathrm{~m}$ de profundidade, o que permitiu abordar um número representativo de locais nas mesmas condições de coleta. Na maioria dos pontos de coleta, a água era oriunda do horizonte não saturado, correspondendo ao nível do freático. Assim, embora não aflore, relaciona-se diretamente com a água de superfície.

A tabela 1 mostra os dados de $\mathrm{CE}$ e $\mathrm{pH}$ de água das três lagoas de referência para o processamento das imagens. A salina 28 é 
notadamente diferente das demais bacias visitadas. Os valores de $\mathrm{pH}$ e CE da água superficial desta salina atingiram, respectivamente, a 10,05 e $54.600 \mu \mathrm{S} / \mathrm{cm}$ enquanto, a $40 \mathrm{~cm}$ de profundidade, $\mathrm{opH}$ foi de 9,87 e a CE de $25.400 \mu \mathrm{S} / \mathrm{cm}$. Estes valores justificam sua escolha como padrão hiperalcalino.

A leitura de pixels dos três corpos d'água (Tabela 2) mostrou comportamento espectral diferenciado nas bandas TM1, 2 e 3, onde a menos salina tem maior reflectância e, notadamente na banda TM4, onde a salina 28 se destaca das demais. A partir destes dados optou-se por uma composição colorida de três razões normalizadas entre as bandas TM: $(5-2) /(5+2) ;(4-3) /(4+3)$ e $(2-1) /(2+1)$ em RGB, com aumento linear de contraste.

Controle do mapeamento e coleta de dados em campo A execução desta fase resume-se em dois pcorecimentos. O primeiro consistiu da identificação e checagem das lagoas com resposta espectral realçada nas imagens TM e classificadas visualmente. A localização destas lagoas fez-se mediante coordenadas obtidas com GPS e seu georeferenciamento lançado em mapa produzido no Laboratório de Informática Geológica do Instituto de Geociências - USP (LIG). A segunda, consistiu da coleta de água e medida de $\mathrm{pH}$ e CE. A ausência de água de superfície na maioria das lagoas implicou na perfuração com trado e coleta água de subsuperfície, cuja relação com a água de superfície é direta, mas em geral mais diluída, como verificado em campo (lagoa 28). Entretanto, em parte das lagoas amostradas a ausência de água do freático necessitou furos mais profundos, de até $3 \mathrm{~m}$, abaixo de camadas de baixa permeabilidade. Nestes casos, a água coletada poderá ter menor correlação com as superficiais e que preenchem as lagoas no período de chuvas.

Utilizou-se um trado tipo holandês, com o qual, após atingido o nível de água (NA), foram obtidas as alíquotas de água subterrânea na porção mais central das lagoas secas e posteriormente medidos os valores de $\mathrm{pH}$ com $\mathrm{pHmetro}$ modelo Digimed devidamente calibrado, e a CE desta água com um condutivímetro eletrônico. Na totalidade das lagoas visitadas buscou-se identificar o

Tabela 1 - Valores de condutividade elétrica e pH das 3 salinas que orientaram o processamento digital das imagens.

\begin{tabular}{|c|c|c|c|}
\hline Lagoas & $\mathbf{2 8}$ & $\mathbf{1}$ & $\mathbf{2 9}$ \\
\hline $\mathbf{p H}$ & 9,33 & 8,04 & 6.25 \\
\hline $\mathbf{C E}(\boldsymbol{\mu}$ S/cm) & 10.370 & 7.140 & 249 \\
\hline
\end{tabular}

Tabela 2 - Valores de radiância das lagoas numeradas como 1 , 28 e 29.

\begin{tabular}{|c|c|c|c|}
\hline Bandas I Lagoas & $\mathbf{2 8}$ & $\mathbf{1}$ & $\mathbf{2 9}$ \\
\hline TM 1 & 18 & 21 & 23 \\
\hline TM 2 & 7 & 6 & 13 \\
\hline TM 3 & 7 & 6 & 13 \\
\hline TM 4 & 30 & 15 & 16 \\
\hline TM 5 & 7 & 8 & 7 \\
\hline TM 7 & 0 & 0 & 0 \\
\hline
\end{tabular}

contexto morfológico (descrição do ângulo, dimensão e continuidade da cordilheira circundante, se presente), evidências de controle biológico fornecido pela fisionomia das coberturas vegetais e por variedades vegetais indicativas de alcalinidade/salinidade e, ainda, indicações do sentido da vazante no local e se a mesma exibia conexão ou não com a lagoa investigada. As amostras de águas superficiais coletadas não constam deste trabalho, devido ao pequeno número e não serem representativas.

RESULTADOS Parâmetros Físico-químicos Os dados de pH e CE de água dos furos de 76 lagoas constam da Tabela 3. Apenas na lagoa de número 44 não se atingiu, com o trado, o nível d'água.

Os dados evidenciam a possibilidade de classificar o universo de lagoas em dois grandes grupos: as que exibem salinidade (eventualmente salobras) e as que não a exibem. Nas primeiras, os resultados obtidos permitem distinguir pelo menos dois grandes grupos, isto é, lagoas hiperalcalinas e lagoas alcalinas. Cada grupo exibe parâmetros físico-químicos de suas águas do aqüífero freático próprios. O grupo 1 tem $\mathrm{pH}>8,0$ e $\mathrm{CE}>5.000 \mu \mathrm{S} / \mathrm{cm}$ e do universo de 77 lagoas, apenas 4 se inserem neste grupo, uma das quais (lagoa 29) com pH 8,04 e CE na casa dos $1.300 \mu \mathrm{S} / \mathrm{cm}$, valor este que a colocaria fora do grupo. O grupo 2 tem alcalinidade entre 7,0 a 8,0 e CE médio superior a $1.000 \mu \mathrm{S} / \mathrm{cm}$ e foram encontradas 14 lagoas no universo analisado. A condutividade, no entanto, é muito variada ( 84 a $3.260 \mu \mathrm{S} / \mathrm{cm}$ ), o que possibilita dividí-las em dois subgrupos, com CE $>1.000$ e $\mathrm{CE}<1.000 \mu \mathrm{S} / \mathrm{cm}$, cada qual com 7 lagoas. $\mathrm{O}$ grupo das lagoas não alcalinas representa a maioria das estudadas, num total de 59 , as quais possuem CE muito variada, com média de $516 \mu \mathrm{S} / \mathrm{cm}$ e com apenas 8 lagoas de CE superior a $1.000 \mu \mathrm{S} / \mathrm{cm}$.

Análise da Imagem TM A compreensão do funcionamento da área implica no entendimento da interação entre os corpos d'água ou bacias, as vazantes e as cordilheiras. A disposição das bacias em relação às cordilheiras é facilmente observada nas imagens e está relacionada às características físico-químicas de suas águas (Capellari 2001). Assim, salinidades significativas impedem a expansão da vegetação da cordilheira em direção à bacia, com a formação de praias detectáveis nas imagens. As diferentes coberturas vegetais e os corpos d'água facilitam a identificação destes elementos em imagens de imagens de satélite, tanto em composições coloridas como em tons de cinza.

A imagem da figura 2 é de composição colorida falsa cor de três razões normalizadas de bandas do sensor TM, isto é, $(5-2) /(5+2)$; $(4-3) /(4+3)$ e $(2-1) /(2+1)$ em RGB. Nesta, as diferentes características da superfície dos corpos d'água está realçada e destaca os principais elementos do sistema. Assim, as vazantes se destacam em tons de rosa e as cordilheiras em amarelo. No tocante aos corpos d'água, observa-se a influência temporal atráz comentada. Em diversas lagoas há mistura de respostas espectrais, refletindo a coexistência, na mesma bacia, de dois momentos evolutivos, um com restos de água no centro, salinizada por evaporação, ensejando o proliferação de algas, enquanto nas bordas a vegetação cresce em solo menos salino (caso de lagoas predominantemente pouco salinas) ou há deposição de matéria orgânica, que ainda subsiste em seu centro (caso das lagoas com elevada CE/ salinas). Por outro lado, coexistem lagoas similares, mas em momentos evolutivos diferentes. Em resumo, uma imagem de satélite não permite classificar o conjunto de corpos d'água de modo confiável e extensivo, por fornecer uma visão instantânea de um ambiente com $\mathrm{pH}$ e CE/salinidade (e biota das águas) evoluindo 
Tabela 3 - Lagoas amostradas e respectivas condutividade elétrica (CE) e pH. Nas lagoas 44 e 64 não se obteve água.

\begin{tabular}{|c|c|c|}
\hline lagoa n. & $\mathbf{C E}(\boldsymbol{\mu S} / \mathbf{c m})$ & $\mathbf{p H}$ \\
\hline 1 & 7140 & 8,04 \\
\hline 2 & 234 & 6,59 \\
\hline 3 & 409 & 6,61 \\
\hline 4 & 312 & 7,11 \\
\hline 5 & 81 & 6,62 \\
\hline 6 & 1190 & 6,69 \\
\hline 7 & 257 & 7,10 \\
\hline 8 & 1240 & 7,06 \\
\hline 9 & 291 & 7,04 \\
\hline 10 & 653 & 6,53 \\
\hline 11 & 620 & 6,71 \\
\hline 12 & 101 & 6,71 \\
\hline 13 & 99 & 6,70 \\
\hline 14 & 249 & 6,29 \\
\hline 15 & 300 & 6,65 \\
\hline 16 & 510 & 6,28 \\
\hline 17 & 237 & 6,42 \\
\hline 18 & 1614 & 6,71 \\
\hline 19 & 707 & 6,38 \\
\hline 20 & 487 & 6,64 \\
\hline 21 & 370 & 6,84 \\
\hline 22 & 505 & 7,45 \\
\hline 23 & 226 & 5,9 \\
\hline 24 & 1684 & 6,68 \\
\hline 25 & 1186 & 6,63 \\
\hline 26 & 888 & 6,55 \\
\hline 27 & 756 & 6,17 \\
\hline 28 & 25400 & 9,87 \\
\hline 29 & 1300 & 8,04 \\
\hline 30 & 678 & 6,79 \\
\hline 31 & 295 & 6,41 \\
\hline 32 & 372 & 6,51 \\
\hline 33 & 1424 & 6,96 \\
\hline 34 & 883 & 7,11 \\
\hline 35 & 81 & 6,20 \\
\hline 36 & 117 & 6,48 \\
\hline 37 & 161 & 6,50 \\
\hline 38 & 531 & 6,72 \\
\hline 39 & 173 & 6,07 \\
\hline 40 & 444 & 5,51 \\
\hline 41 & 534 & 6,37 \\
\hline & & \\
\hline
\end{tabular}

\begin{tabular}{|c|c|c|}
\hline lagoa $n$. & CE $(\mu \mathrm{S} / \mathrm{cm})$ & pH \\
\hline 42 & \begin{tabular}{|l|}
774 \\
\end{tabular} & 6,39 \\
\hline 43 & 1885 & 6,54 \\
\hline 44 & seca & - \\
\hline 45 & 3180 & 7,58 \\
\hline 46 & 420 & 6,73 \\
\hline $47 *$ & 3260 & 7,52 \\
\hline $48^{*}$ & 779 & 6,55 \\
\hline $49 *$ & 30 & 6,35 \\
\hline $50^{*}$ & 2160 & 7,26 \\
\hline $51 *$ & 191 & 6,59 \\
\hline $52 *$ & 98 & 6.48 \\
\hline 53 & 288 & 6,37 \\
\hline 54 & 469 & 6,80 \\
\hline 55 & 512 & 6,61 \\
\hline 56 & 1505 & 7,06 \\
\hline 57 & 204 & 6,69 \\
\hline 58 & 177 & 6,72 \\
\hline 59 & 394 & 6,68 \\
\hline 60 & 307 & 6,07 \\
\hline 61 & 392 & 6,60 \\
\hline 61 & 392 & 6,60 \\
\hline 61 & 392 & 6,60 \\
\hline $62 *$ & 5540 & 9,14 \\
\hline $62 \mathrm{a}^{*}$ & 98 & 7,14 \\
\hline $63 *$ & 233 & 6,84 \\
\hline $64 *$ & seca & \\
\hline $65^{*}$ & 84 & 7,11 \\
\hline $65 \mathrm{a}^{*}$ & 392 & 7,27 \\
\hline 66 & 514 & 6,56 \\
\hline 67 & 336 & 6,20 \\
\hline 68 & 375 & 6,88 \\
\hline 69 & 737 & 6,74 \\
\hline 70 & 1588 & 7,15 \\
\hline 71 & 382 & 6,37 \\
\hline 72 & 450 & 6,74 \\
\hline 73 & 1462 & 7,10 \\
\hline 74 & 1104 & 6,44 \\
\hline 75 & 166 & 6,39 \\
\hline 76 & 1104 & 6,40 \\
\hline 77 & 184 & 6,06 \\
\hline
\end{tabular}

contínua e rapidamente ao longo do ano. Mas os resultados obtidos, entendidas as limitações descritas, são confiáveis na indicação preliminar do tipo de lagoa e baía, se complementado com a classificação de campo a partir dos parâmetros físico-químicos, e como subsídio para estudos de identificação, classificação e gê- nese das lagoas e do sistema como um todo.

Entretanto, os elementos do ambiente são claros nas imagens, tanto em composições coloridas de bandas originais como de razões de bandas. Assim, o conjunto de cordilheiras se manifesta (Fig. 2), em amarelo devido à resposta de vegetação mais expressiva, comumente arbórea (cerradão) realçada pelas razões normalizadas das bandas TM 5/2 e 4/3, respectivamente nos canais R e G. As vazantes aparecem em rosa devido em parte à alta reflectância na banda TM5 das savanas de gramíneas que cobrem parcialmente areias. As vazantes, deviso à ausência de vegetação, estão bem definidas nas imagens, as quais indicam ainda um fluxo da água de $\mathrm{NE}$ para SE, como de fato ocorre. Em meio às vazantes, a imagem revela áreas alongadas de vegetação arbóreo-arbustiva, interpretadas como resquícios de cordilheiras. Freqüentemente preservam parte da sua forma original, dispondo-se como segmentos de círculo. Assim, as imagens mostram lagoas completamente cercadas por cordilheiras, as quais, no campo, são mais profundas e com maior e mais íngremes diferenças de altitude com as cordilheiras. Estas cordilheiras, quando com vegetação, protegem os corpos d'água das vazantes. Próximo a estes corpos d'água ocorrem outros apenas parcialmente protegidos por cordilheiras descontínuas e, finalmente, há lagoas soltas nas vazantes, as quais, no campo, são pouco definidas e de pouca profundidade.

A figura 2 abrange a fazenda da Embrapa, e proximidades. A figura não mostra as lagoas estudadas nas fazendas mais distantes por se situarem até dezenas de quilômetros dos limites leste e sul do centro da imagem. Isto impossibilitou a representação destas em escala adequada.

Outro aspecto não sazonal e evidente nas imagens após os trabalhos de campo, é a correlação de lagoas de alta salinidade e pH com áreas protegidas por cordilheiras íntegras, contínuas, como definido em Almeida \& Lima (1959) e mapeado em detalhe por Capellari (2001). Embora este aspecto esteja bem descrito, a observação da imagem à luz dos dados de campo permite avançar na compreensão da evolução dos corpos d'água, seja nos parâmetros físico-químicos de suas águas, seja no aumento da sua alcalinidade e salinidade, ao adicionar uma visão sinóptica. Exemplo notável é um conjunto de três lagoas interligadas em série (Fig. 3), no qual o ingresso inicial da água da vazante (setas em azul) ocorre pela lagoa 71 (pH 6,37 e CE de $382 \mu \mathrm{S} / \mathrm{cm}$ ), passando desta para a lagoa 69 (pH 6,74 e CE de $737 \mu \mathrm{S} / \mathrm{cm}) \mathrm{e}$, finalmente, desta para a lagoa 70 ( $\mathrm{pH} 7,15$ - grupo das alcalinas - e CE de $1588 \mu \mathrm{S} / \mathrm{cm}$ ). Nas imagens, observa-se que as lagoas 69 e 71 têm cor marrom e a lagoa 70 tem todo seu centro com cor azul claro, como ocorre com a maior parte das lagoas de $\mathrm{pH}$ alcalino.

As 77 lagoas visitadas permitem entender as respostas espectrais daquelas feições nas imagens. Do ponto de vista do sensoriamento remoto, a alcalinidade condiciona a atividade biológica e esta a resposta espectral. Entretanto, para as respostas na imagem, as relações são mais ligadas à salinidade do que à alcalinidade.

Assim, nas lagoas sem praia, encontrou-se, em furos de trado de 1 a 3m, águas ligeiramente ácidas a ácidas, com baixa CE denotando baixa salinidade. Nestas, as cordilheiras, quando presentes, apresentam pequeno desnível e são em geral descontinuadas, cobertas por vegetação arbustiva e densa e, se arbórea, apresentam um sub-bosque fechado. No trabalho de campo estavam secas em sua quase totalidade e cobertas por vegetação, salvo a parte central, comumente com o solo, em círculo quase perfeito, revirado por porcos selvagens. A vegetação apresenta nítido zoneamento, variando as espécies, predominantemente gramíneas, podendo aparecer nas imagens como círculos concêntricos. Nas 


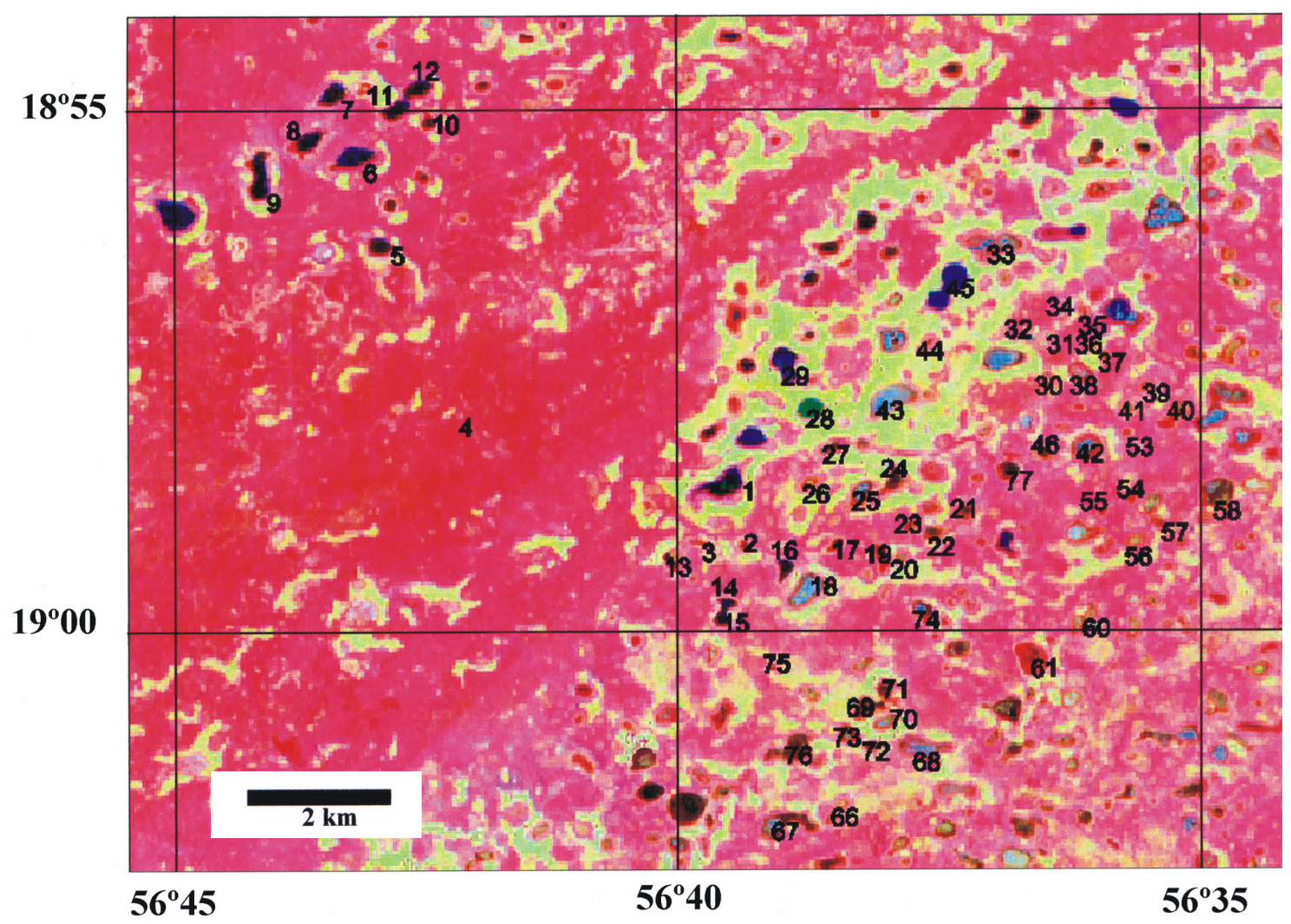

Figura 2 - Composição colorida falsa cor das razôes de bandas (5-2)/(5+2); (4-3)/(4+3) e (2-1)/(2+1), em RGB, da imagem LANDSAT-TM5 de 21 de outubro de 1990, com as lagoas estudadas. Em vermelho e rosa são áreas de campo e em amarelo vegetação predominantemente arbórea sobre as cordilheiras.

imagens estas lagoas aparecem em negro, marrom e azul marinho.

As lagoas alcalinas, eventualmente neutras, têm alta salinidade. Estas têm também vegetação de fundo, em geral seco durante o trabalho de campo. Nas imagens, das 14 lagoas nesta condição, 8 apresentam cor azul claro, 3 negra e 2 verde escuro. As cordilheiras se assemelham às do grupo anterior, tanto em desnível como na cobertura vegetal.

O grupo das hiperalcalinas com CE médio próximo de 10.000 $7.000 \mu \mathrm{s} / \mathrm{cm}$ respondem de forma clara, com as 4 lagoas em verde brilhante e negro com porções verde escuro, verde claro e verde azulado. Entretanto, no campo, distinguem-se claramente das anteriores, com cordilheiras contínuas, arbóreas, com presença muito freqüente da palmeira carandá, Copernicia Alba (Morang.) e maiores declives na face da cordilheira voltada para a bacia, bem como praias de areia. Finalmente, as lagoas com condutividade superior a $7.000 \mu \mathrm{S} / \mathrm{cm}$ e $\mathrm{pH}$ superior a 8 encontradas por Capellari (2001) na área de estudo, apresentam, na imagem, cores verde brilhante, verde azulado e azul esverdeado, sempre distintas das demais lagoas, como ocorre com a lagoa 28. Em toda porção de Nhecolândia abrangida pela imagem Landsat verifica-se que as lagoas com respostas espectrais similares a estas estão sempre protegidas por cordilheiras contínuas, reforçando a interpretação da correlação entre a resposta espectral e valores extremos de $\mathrm{pH}$ e salinidade.

DISCUSSÃO O atual estágio do conhecimento aponta para um complexo conjunto de parâmetros que controlam a alcalinidade/ salinidade destas lagoas, resultante de uma conjugação de fatores morfológicos, hidrogeológicos, de cobertura vegetal e de variações climáticas. Por outro lado, os lagos não alcalinos resultam da ação das águas das vazantes.

As lagoas protegidas pelas "cordilheiras" íntegras, com cobertura vegetal arbórea, pouco são influenciadas pelas vazantes (controle hidrológico, com afluxo de água não alcalina). No período de estiagem, estas lagoas adquirem alcalinidade e salinidade, podendo apresentar bloom algal. Com a estiagem prolongada ocorre a precipitação da matéria orgânica e sais dissolvidos. A concentração destes solutos tende a aumentar nos períodos climáticos cíclicos, onde a estação de seca é mais agressiva, responsáveis por um aumento da alcalinidade e do conteúdo de solutos (sais bicarbonatados de sódio, magnésio etc).

A figura 4 mostra uma mesma área imageada em 1990 (Landsat 5) e em 2002 (Landsat 7). Esta exibe um exemplo claro da proteção das cordilheiras pela vegetação. Na imagem de 1990, as lagoas assinaladas com A, C e D estão menos protegidas pelas cordilheiras nesta área de vazante. Em 2002, as mesmas lagoas mostram notável avanço das cordilheiras, evidenciada pela vegetação em amarelo, aumentando seu grau de proteção. Observe-se que as lagoas adquirem contornos melhor definidos e exibem marca de praia, bem destacado na lagoa assinalada como D'. O processo inverso pode ser observado na lagoa B em 1990 e B' em 2002, a qual está descaracterizada pela ação da vazante. Outros exemplos poderiam ser apontados nestas imagens.

$\mathrm{O}$ conjunto das três lagoas interligadas em série da figura 3 
indica modificação da água ácida da vazante, com o aumento gradual de $\mathrm{pH}$ e CE associado ao nível de proteção e isolamento oferecido pelas cordilheiras. Observa-se neste caso uma clara evolução de uma lagoa ácida e pouco salina ( $\mathrm{pH}$ de 6,37 e CE de $382 \mu \mathrm{S} / \mathrm{cm}$ ) para uma lagoa levemente alcalina e salina ( $\mathrm{pH}$ de 7,35 e CE de $1588 \mu \mathrm{S} / \mathrm{cm})$.

O conjunto de informações de sensoriamento remoto e de campo permite sugerir, ainda, uma hipótese de modelo evolutivo das lagoas, mesmo que não contemplando o seu todo. Lagoas alcalinas tem fundo mais impermeável, protegendo-as da variação do lençol freático, como já descrito (Barbiero et al. 2000, 2002). Coma

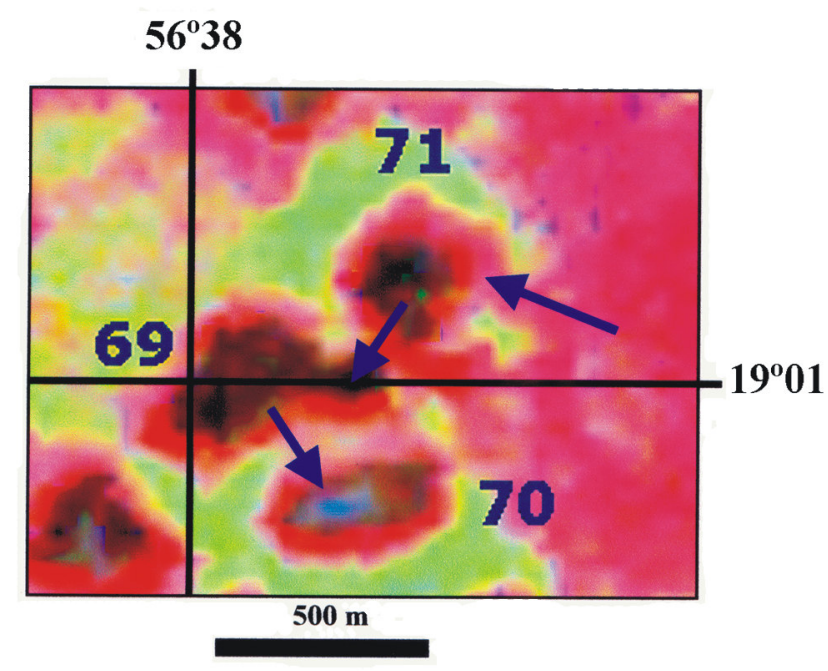

Figura 3 - Detalhe da figura 2 mostrando a localização das lagoas 69, 70 e 71, interligadas em série. Observar tonalidade azul na lagoa 70, de maior pH e CE. As setas em azul mostram o percurso das águas. invasão por águas ácidas, por oscilação sazonal do lençol freático e ação das vazantes, ocorreria acidificação e assoreamento parcial de uma dada lagoa alcalina, alterando seu equilíbrio ecológico ao acidificar as águas e diminuir o gradiente topográfico do fundo das lagoas ao topo das cordilheiras. Este desequilíbrio incluiria as cordilheiras e sua vegetação, com perda dos indivíduos arbóreos, tornando toda a cordilheira sujeita à erosão pela água de chuva e de inundação, processos que terminariam por assorear mais as antigas lagoas. Ao fim do processo, restariam apenas áreas circulares de solo e umidade diferenciada em meio às vazantes, como observado nas imagens e no campo.

A porção correspondente ao aqüífero freático destas lagoas alcalinas/hiperalcalinas, rica em solutos, passa a operar como cunha salina nas cordilheiras adjacentes, que exibem valores de alcalinidade e salinidade não correspondentes ao observado tanto na água subterrânea das lagoas como na água superficial das mesmas. A lagoa 62 (UTM 553000E, 7888381N) mostra evidências desta cunha, uma das indicadas pela imagem como hipersalina em localidade distante da fazenda da Embrapa, apresentou $\mathrm{pH}$ de 9,14 e CE de $5.540 \mu \mathrm{S} / \mathrm{cm}$ em água obtida em furo de trado raso $(70 \mathrm{~cm})$ na areia da praia. A alguns metros, no limite com a cordilheira, em furo de 1,9m, a água apresentou $\mathrm{pH}$ de 7,10 e CE de $98 \mu \mathrm{S} / \mathrm{cm}$.

CONCLUSÕES 1. Há claras evidências, em campo e nas imagens TM, do controle da vegetação na evolução do ambiente, tanto por permitir uma resistência à erosão e transporte de sedimentos pelas vazantes como na proteção diferenciada das bacias internas às cordilheiras, permitindo sua diversidade físico-química e biológica;

2. A presença de Copernicia Alba (Morang.), vulgarmente conhecido como Carandá (Conceição e Paula 1988), em todo o entorno da lagoa definida como hiperalcalina e a presença nas cordilheiras de lagoas de alta CE, é forte indicação geobotânica da convivência desta espécie com ambientes alcalinos e de salinidade acima da média para a região. Esta variedade também é freqüente
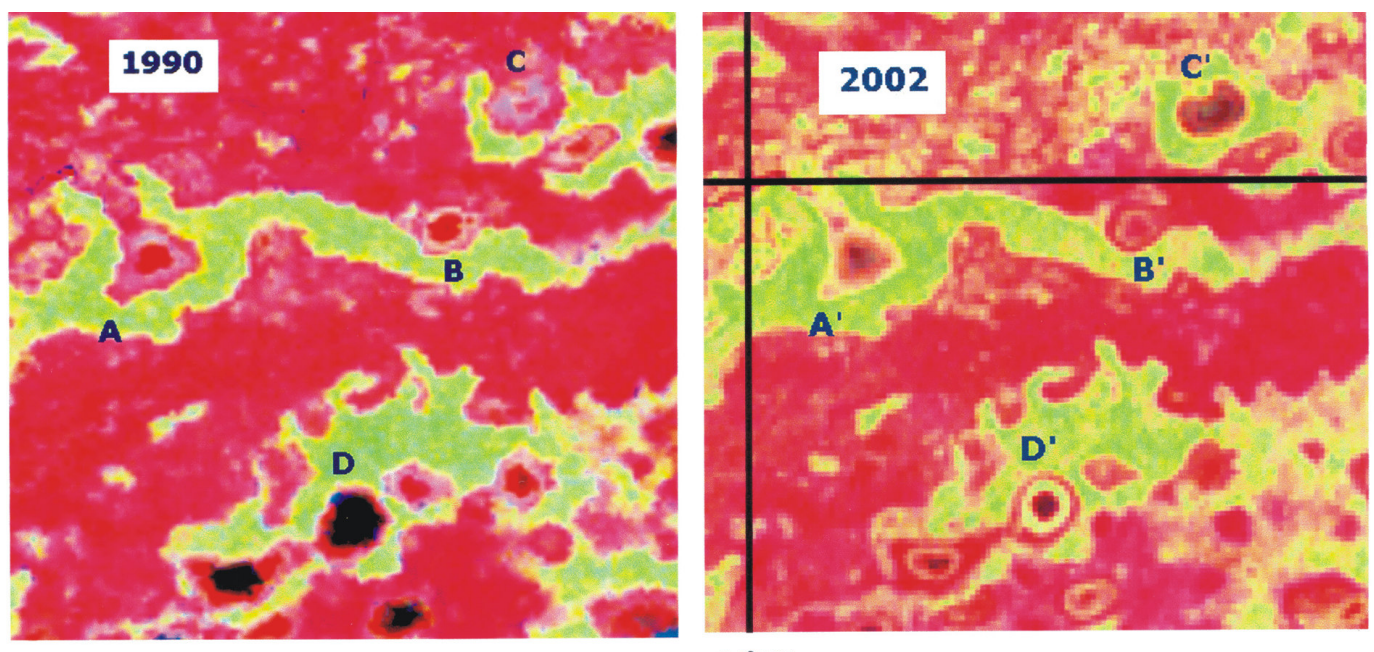

$18^{\circ} 55$

\section{$56^{\circ} 39^{\prime}$}

$500 \mathrm{~m}$

Figura 4 - À esquerda detalhe da figura 2 (imagem TM de 21 de outubro de 1990) mostrando área de vazante limitadas por cordilheiras em verde amarelado e à direita imagem ETM+ Landsat 7 de 28 de setembro de 2002 do mesmo local e com o mesmo processamento digital. Notar que em 12 anos as lagoas A, C e D tornaram-se mais protegidas e mais definidas, ocorrendo o inverso com a lagoa $B$. 
nas lagoas alcalinas, inexistente nas não alcalinas. Observe-se que outra palmácea de mesmo porte da região, a Bocaiúva (Acrocomia sclerocarpa Mart.), não foi identificada qualquer associação geobotânica,

3. Pelos resultados obtidos, fica claro que as lagoas hiperalcalinas e alcalinas estão protegidas, integral ou parcialmente, da ação das vazantes pelas cordilheiras ao seu redor,

4. Confirma-se que a lagoa hiperalcalina tem fundo topograficamente mais rebaixado, mas inferior a $4 \mathrm{~m}$, do que as vizinhas, pouco menos rebaixadas, as quais também têm fundo rebaixado se comparadas com as lagoas de contato direto com as vazantes e não alcalinas,

5. Confirma-se que a aplicação de sensoriamento remoto multiespectral óptico permite realçar respostas espectrais de origem biológica, mas diretamente associadas às características físico-químicas das águas.

6. A análise do conjunto de dados de campo e de sensoriamento remoto permite sugerir:

- aumento sucessivo de alcalinidade e salinidade em lagoas con- tíguas em que apenas a primeira está ligada à vazante, com as demais sendo alimentadas em série, implicando em concentração gradual (em cada lagoa) de pH e CE;

- hipótese para parte da evolução deste conjunto de lagoas do Pantanal da Nhecolândia: lagoas de alta alcalinidade evoluiriam para de baixa alcalinidade e estas para lagoas ácidas, simultaneamente a um processo de assoreamento e de substituição da cobertura vegetal arbórea das cordilheiras, em processo de erosão, por coberturas vegetais menos expressivas.

7. Observa-se ocorrer uma variabilidade espacial dos teores de concentração de soluto nas lagoas o que demonstra que podem ocorrer processos de concentração diferenciados, condicionados pelos elementos do meio, ainda sem resposta.

Agradecimentos À responsáveis pela Fazenda da EMBRAPA (Fazenda Nhumirim), no Pantanal, à Secretaria do Meio Ambiente do MS e a UFMS pelo apoio logístico de campo e estadia, à Dra. Wania Duleba pela cessão da imagem ETM+ de 2002 e aos revisores da RBG pelas sugestões ao manuscrito.

\section{Referências}

Ab'Saber A.N. 1988. O Pantanal Mato-grossense e a teoria dos refúgios. Rev. Brás. de Geogr., 50:9-57, Tomo 2.

Almeida F.F.M. \& Lima M.A. 1959. Planalto Centro-Ocidental e Pantanal Mato-Grossense. In: União Geográfica Internacional, Cong. Internacional de Geografia, 28, Rio de Janeiro, 169 p.

Antas P.T.Z. \& Nascimento I.L.S. 1996. Tuiuiú. Ed. Empresa das Artes, São Paulo, 170p.

Barbiéro L., Queiroz Neto J.P., Ciornei G., Sakamoto A., Fernandes E., Capellari B., Valles V. 2002. Geochemistry of water and groundwater in the Nhecolândia, Pantanal of Mato Grosso, Brazil. Variability and associated processes. Wetlands, 22:528-540.

Barbiéro L., Queiroz Neto J.P., Ciornei G., Sakamoto A., Capellari B. 2000. Geoquímica das águas de superfície e dos lençóis freáticos da Nhecolândia, Pantanal de Mato Grosso (MS, Brasil). In: Simp. Rec. Naturais e Sócio-econômicos do Pantanal, 3, Corumbá, Anais.

Brasil 1982. Geologia da folha SE 21 Corumbá. Geologia, geomorfologia, pedologia, vegetação e uso potencial da Terra. Levantamento de Recursos Naturais. RADAMBRASIL, Min. Das Minas Energia, 27, 448pp. Brasília.

Braun E.H.G. 1977. Cone Aluvial do Taquari, unidade geomórfica marcante na planície quaternária do Pantanal. Rev. Bras. Geoc., 39:164180.

Brivio P.A., Giardino C., Zilioli E. 2001. Validation of satellite data for quality assurance in lake monitoring applications. The Science of the Total Environment, 268:3-18.

Capellari B. 2001. Sensoriamento remoto aplicado ao estudo da dinâmica hidrológica da região da Nhecolândia, Pantanal Matrogrossense, MS. Dissertação de Mestraado, FFLCH-USP, 100p.

Carvalho N.O. 1986. Hidrologia do Alto Paraguai. In: Simp. Recursos Naturais e Sócio-econômicos do Pantanal, 1, Corumbá, Anais, pp. 63-76.

Clapperton C. 1993. Quaternary geology and geomorphology of South America. Elsevier, 779p.

Conceição C.A. \& Paula J.E. 1988. Contribuição para o conhecimento da flora do Pantanal mato-grossense e sua relação com a fauna e o homem. In: Simp. Recursos Minerais e Sócio-Econômicos do Pantanal, 1, Corumbá, Anais, pp. 107-130.
Cunha J. 1943. Cobre do Jaurú e Lagoas alcalinas do Pantanal (Mato Grosso). Departamento Nacional da Produção Mineral, Boletim 6, $54 \mathrm{p}$.

Fernandes E. 2000. Caracterização dos elementos do meio físico e da dinâmica da Nhecolândia-Pantanal Sulmatogrossense. Dissertação de Mestrado, FFLCH, USP, São Paulo..

Fernandes E., Sakamoto Y.A., Queiroz Neto J.P. de, Lucati H.M., Capellari B. 1999. Le "Pantanal da Nhecolândia" cadre physique et Dynamique hydrologique. In: Conf. Intern. Géomorphologie, 4, Bologna, Italia, Supplemento di Geografia Fisica e Dinâmica quaternaria, Comitato Glaciologico Italiano, v. 22, p. 13-21, Torino.

Hamilton S.K., Sippel S.J., Melack J. M. 1995. Oxygen depletion and carbon dioxide and methane production in waters of the Pantanal wetland of Brazil. Biogeochemistry, N. 30, pp. 115-141.

Hamilton S.K., Sippel S.J., Melack J.M. 1996. Inundation patterns in the Pantanal wetland of South America determined from passive microwave remote sensing. Arch. Hydrobiol. 137:1-23.

Klammer G. 1982. Die Paläowüste des Pantanal von Mato Grosso und die pleistozäne Klimageschichte der brasilianischen Randtropen. $Z$. Geomorphologie, 26:393- 416, Berlin-Stuttgart.

Oliveira A.I. \& Leonardos O.H. 1943. Geologia do Brasil. $2^{a}$ Edição. Série didática no 2. Ministério da Agricultura. 813p.

Tricart J. 1984. Le Pantanal (Brésil) etude écogéographique. Travaux et Documentos de Géographie Tropicale. CEGET, n.52, Bordeaux.

Ussami N., Shiraiwa S., Dominguez J. M. L. 1999. Basement reactivation in a sub-Andean foreland flexural bulge: The Pantanal wetland, SW Brazil. Tectonics, 18:25-39.

Valverde O. 1972. Fundamentos Geográficos do planejamento rural do Município de Corumbá. Rev. Bras. Geogr., 34:49-144.

Weyler G. 1962. Relatório final dos Poços perfurados no Pantanal Matogrossense. Projeto Pantanal. Distrito de Expl. Sedimentar do Paraná, Petrobrás, Ponta Grossa-PR, 27p.

Manuscrito SR-11

Recebido em17 de novembro de 2002

Revisão dos autores em 10 de março de 2003

Revisão aceita em 01 de abril de 2003 